\title{
Nerve transfers in distal forearm and in the hand
}

\author{
Alfio Luca Costa ${ }^{1}$, Paolo Titolo², Bruno Battiston ${ }^{2}$, Michele Rosario Colonna ${ }^{1}$ \\ 'Department of Human Pathology of the Adult, the Child and the Adolescent, University of Messina, Messina 98125, Italy. \\ ${ }^{2}$ Depatment of Traumatology, Azienda Ospedaliero-Universitaria Citta della Salute e della Scienza di Torino, Turin 10126, Italy.
}

Correspondence to: Dr. Costa Alfio Luca, Department of Human Pathology of the Adult, the Child and the Adolescent, University of Messina, Via Consolare Valeria 1, Messina 98125, Italy. E-mail: alfiocosta@hotmail.it

How to cite this article: Costa AL, Titolo P, Battiston B, Colonna MR. Nerve transfers in distal forearm and in the hand. Plast Aesthet Res 2020;7:32. http://dx.doi.org/10.20517/2347-9264.2020.43

Received: 20 Mar 2020 First Decision: 21 May 2020 Revised: 7 Jun 2020 Accepted: 7 Jun 2020 Published: 24 Jun 2020

Science Editor: Alessandro Thione Copy Editor: Cai-Hong Wang Production Editor: Jing Yu

\begin{abstract}
Nerve transfers were used, originally, to restore shoulder and elbow function in brachial plexus lesions. This concept has been developed over the years and applied to distal nerve injuries in which lower functionality was expected because of the gap between the injury site and the target muscle. The aim of this review is to describe nerve transfers in the distal forearm and hand for isolated lesions of the median, ulnar and radial nerves. The different advantages achieved by transposition of a functional nerve stump near the effector muscle have opened up new options for the management of nerve lesions. Some of these alternatives have only been recently reported and a few are exclusively case reports.
\end{abstract}

Keywords: Nerve transfers, nerve injury, hand surgery, babysitting, coaptation, microsurgery

\section{INTRODUCTION}

Nerve transfers were originally adopted for brachial plexus lesions to restore shoulder and elbow function ${ }^{[1-3]}$. This concept has been developed over the years and now, applied to distal nerve injuries ${ }^{[4]}$ in which poor functional outcomes were anticipated because of the gap between the injury site and the innervated muscle. The aim of this review is to describe nerve transfers in the distal forearm and hand for isolated lesions of the median, ulnar and radial nerves. 


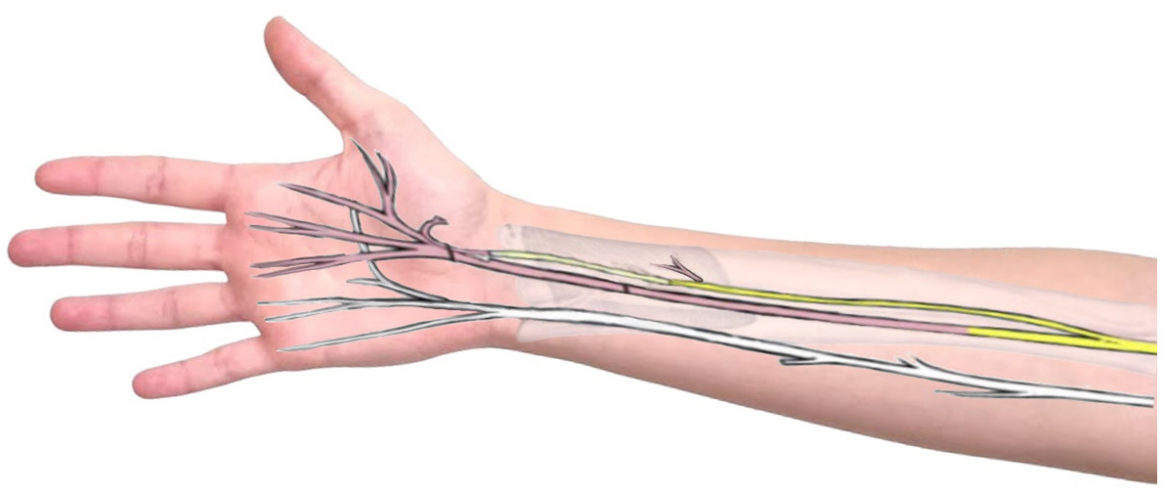

Figure 1. Anterior interosseous nerve (AIN) for thumb opposition. The axons of AIN at the level of pronator quadratus are coapted to the thenar branch of median nerve, through a nerve graft. Yellow: functional nerve; pink: nonfunctional nerves

\section{MOTORY NERVE TRANSFERS}

\section{Median nerve}

The median nerve provides a large part of sensitivity to the palmar side of the hand, which is critical for fine manipulation. It innervates and enables forearm pronation, has the most important role in wrist and finger flexion, especially the thumb and index fingers, and plays a significant part in thumb opposition.

Depending on the location and severity of nerve injury, different interventions are possible ${ }^{[5-7]}$.

In the distal forearm and in the hand, thumb opposition and restoration of sensibility of the thumb and index finger are the main objectives of reconstruction.

Motor nerve transfers in the distal forearm and hand

Median nerve injuries, at all levels, are associated with atrophy of the thenar eminence and loss of thumb opposition. Infrequently, atypical innervation patterns from the ulnar nerve can preserve opposition, and these have to be evaluated closely ${ }^{[6]}$.

In lesions of the motor fascicles of the median nerve, direct repair or interposition of a graft remains the treatment of choice.

When the anatomy is significantly altered however, direct repair can lead to suboptimal results as the nerve at this level is mainly sensory and, proximally, the scheme of the motor neurons is undefined ${ }^{[8-10]}$. An interpositional nerve graft could result in abnormal regeneration in which sensory fibers branch out into the motor fibers, and consequently without thenar function.

To obtain opposition of the thumb, tendon transfers are very effective, but it should be emphasized that these procedures require long periods of reeducation and lead to abnormal ergonomics.

If available, the anterior interosseous nerve (AIN) is dissected at the level of the branch to the pronator quadratus and coapted [Figure 1] to the thenar branch of the median nerve (TBMN). The AIN, at this level, is composed mainly of motor fibers with only sensory branches for proprioception of the wrist ${ }^{[11]}$, with a congruous number of axons (distal AIN 900; thenar motor branch $\sim 1,050^{[10,12]}$ ). It should also be mentioned that this technique requires the use of a nerve graft, which inevitably leads to a loss of the total number of fibers. 


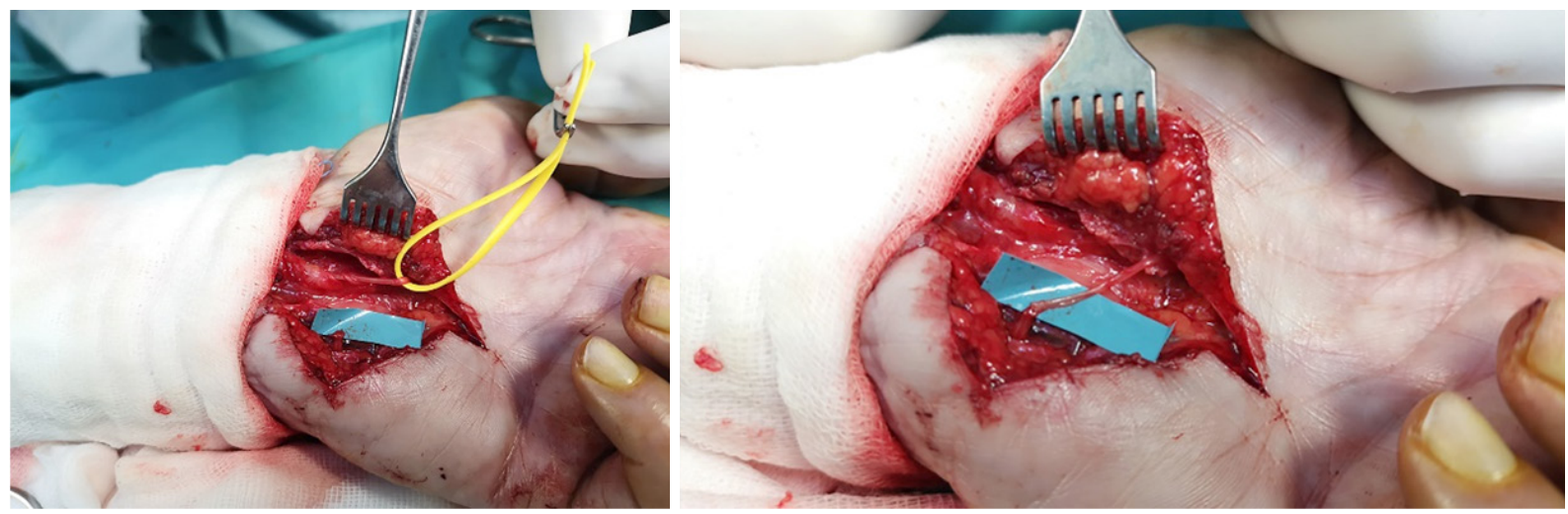

Figure 2. Transfer between the motor branch of the abductor digiti quinti (ADQMB) and the thenar branch of the median nerve. This branch is released proximally for $2 / 3 \mathrm{~cm}$ and coapted end to end towards the ADQMB branch

Reinnervation of the muscles of the thenar eminence by direct nerve repair is impossible in high median nerve injuries, due to the long distance that the nerves have to traverse for regeneration. Nerve transfers involving the ulnar (third lumbrical motor branch) ${ }^{[13]}$ and radial nerve (motor branch to the extensor digiti minimi and extensor carpi ulnaris) have been proposed, but until a few years ago, results were still ambiguous and consequently, classical tendon transfers were preferred ${ }^{[4]}$. Bertelli et $_{\text {al }}{ }^{[14]}$ recently described promising results after nerve transfer between the motor branch of the abductor digiti quinti (ADQMB) and the TBMN in which the ADQMB is dissected as distally as achievable, and then coapted to the TBMN without nerve grafting ${ }^{[14]}$ [Figure 2].

\section{Anterior interosseous nerve to median recurrent motor branch transfer: technique}

The surgeon opens the carpal tunnel to identify the median nerve and follows it to the origin of the TBMN, close to the thenar eminence. In the distal forearm, the flexor digitorum superficialis and profundus are retracted to expose the pronator quadratus and the median nerve. The AIN and the nerve branch to the pronator quadratus are identified. The pronator quadratus is then dissected superior to the median nerve with intramuscular dissection to obtain the maximum length.

An interpositional nerve graft (frequently the sural nerve or medial antebrachial cutaneous) is usually necessary for tensionless suture. Range of motion of the wrist should be assessed before utilizing the graft to ensure that hand movement will not generate excessive stress on the coaptation.

\section{Abductor digiti quinti motor branch to the recurrent motor branch transfer: technique}

A lazy $\mathrm{S}$ incision is made on the lateral margin of the hypothenar region, Guyon's canal is opened, and the motor branch of the ulnar nerve is identified and followed distally. The branch for the abductor digiti minimi is dissected and its function assessed with an electrical stimulator. After that, the surgeon opens the carpal tunnel to visualize the median nerve. In the median nerve, the origin of the TBMN is identified near the thenar eminence. This branch is divided proximally for $2 / 3 \mathrm{~cm}$ and coapted end-to-end towards the ADQMB branch.

\section{UInar nerve}

As a result of injury to the ulnar nerve, grip and pinch weakness, and sometimes, clawing of the last two ulnar digits occurs ${ }^{[15,16]}$. For proximal injuries, direct coaptation should reestablish sensation to the ulnar digits ${ }^{[17-20]}$. However, after an immediate direct ulnar nerve repair, it is not possible to achieve recovery of the innervation of the intrinsic musculature due to the long distance that the neurons must traverse for nerve regeneration ${ }^{[18]}$. Classical tendon transfers prevent deformities such as clawing, but they are often 


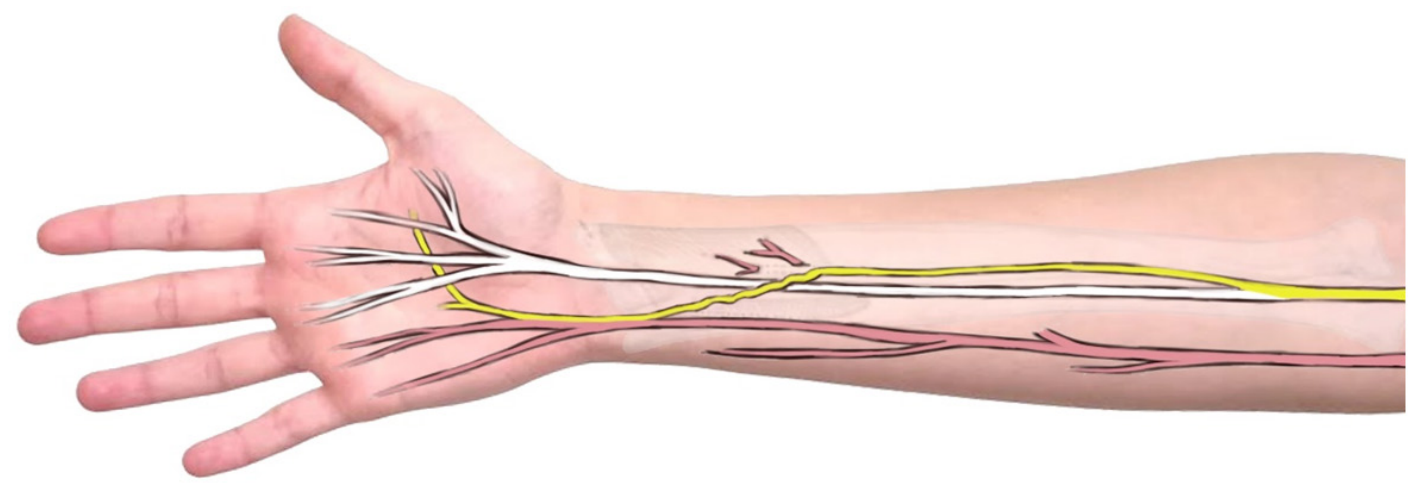

Figure 3. Anterior interosseous nerve (AIN) to ulnar deep motor transfer. The AIN is followed into the pronator quadratus. Proximal neurolysis of the motor fascicle of the ulnar nerve enables tensionless coaptation. Yellow: functional nerves; pink: nonfunctional nerves

associated with a loss of strength and fluidity of movement. In isolated lesions of the ulnar nerve, various techniques reported in the literature involve the median nerve as a donor of motor and/or sensitive fibers in the distal forearm and in the hand ${ }^{[21-24]}$. The preferred motor donor is the distal AIN to restore functionality of the intrinsic musculature. It is possible to achieve neurolysis of the motor branch of the ulnar nerve for up to 14 centimeters proximally to the radial styloid, allowing adequate length to achieve tensionless coaptation with the AIN donor branch [Figure 3]. In cases of injury to both the ulnar and median nerves, the radial nerve can act as a fiber donor.

\section{Motor nerve transfers in forearm}

When there are no median nerve injuries, the anterior interosseous nerve in its distal portion directed to the pronator quadratus muscle can be used as a fiber donor for the motor component of the ulnar nerve. Brown et al ${ }^{[25]}$ performed the first such case in 1991 and several authors have since successfully reported this technique.

This technique is frequently executed end-to-end, and proximal neurolysis of the ulnar nerve avoids the need for a nerve graft. Battiston and Lanzetta showed good results in seven patients who underwent terminal anterior interosseous nerve-to-ulnar motor nerve transfer in distal forearm, proximal to Guyon's canal $^{[22]}$.

Brown and Mackinnon ${ }^{[4]}$ have shown that neurolysis up to $14 \mathrm{~cm}$ proximal to the radial styloid can be performed for the ulnar nerve.

The reverse end-to-side or "supercharge" nerve transfer ${ }^{[26,27]}$ can also improve intrinsic function and allow the ulnar nerve to regenerate spontaneously ${ }^{[28]}$.

Barbour et al. ${ }^{[28]}$ also suggested through their experience in nerve transfers to the ulnar nerve that supercharged coaptations can keep the motor end plates good, as well as serve as a "babysitter", until "native parent" axons return.

With validation of the idea that axons can regenerate if a nerve is sutured in end-to-side fashion, supercharged end-to-side (SETS) nerve transfers began to be used ${ }^{[29]}$.

In a retrospective matched-cohort study, Baltzer et al. ${ }^{[30]}$ compared the outcomes of supercharged end-toside procedures with the conventional technique in patients with a high ulnar nerve injury. As a result, the group in which the AIN SETS was implemented had better results and recovery of the intrinsic functionality of the hand. 
Koriem et al. ${ }^{[31]}$ directed a prospective study in 21 patients with a high ulnar nerve injury. In 10 patients, the lesion was managed through direct and isolated repair of the ulnar nerve (UR) while in the remaining 11 patients, the repair was associated with a supercharged end to side (SETS) nerve transfer. In the latter group, the patients showed improvement at six months' follow-up, which is a shorter time than necessary to regenerate ulnar nerve fibers from the lesion.

In 2010, Sherif and $\mathrm{Amr}^{[32]}$ demonstrated that a double bridging nerve graft between the motor components of the ulnar and median nerve in the distal forearm could prevent atrophy of the intrinsic muscle until proximal nerve regeneration can arrive at these effectors.

These authors reported the best results in median nerve effector protection, and a good result regarding the ulnar nerve with the creation of an artificial Martin-Gruber connection through a double end-to-side bridge graft. In the same way, Colonna et al. ${ }^{[33]}$ reported a double end-to-side coaptation via a nerve graft enabled fibers from the donor median nerve to regenerate the injured ulnar nerve

Anterior interosseous nerve to ulnar motor branch transfer technique

A lazy S incision at the level of Guyon's canal and dissection of the pronator quadratus muscle allows exposure of the ulnar and median nerves at the level of the distal forearm. At the level of Guyon's canal, it is possible to identify sensory and motor branches of the ulnar nerve; internal neurolysis of the motor fibers of the ulnar nerve proceeds as proximally as possible and finally these are divided. The anterior interosseous nerve is followed as it enters the pronator quadratus muscle and divided as distally as possible. The proximal stump of the anterior interosseous nerve is then coapted end-to-end to the distal stump of the motor branch of the previously dissected ulnar nerve.

\section{Motor nerve transfer in the distal palm}

Barbour et al. ${ }^{[34]}$ reported transfers from the branch of the posterior interosseous nerve (specifically, branches from the extensor digiti minimi and extensor carpi ulnaris) with sub-optimal results.

This demonstrates the inconsistent pattern of reinnervation seen when reinnervating numerous motor functions with an inadequate number of donor nerves.

The TBMN has been used in recent years as a fiber donor in the palm to restore function of the deep motor branch of the ulnar nerve. Aszmann and Gesselbauer ${ }^{[35]}$ built on Riche-Cannieu's ulnar-to-median nerve communication in the palm and proposed a distal babysitting technique via a nerve graft between the thenar branch of the median nerve (donor) and the ulnar nerve "just distal to Guyon's canal". At long-term follow-up at 6 years, they presented very promising results with intrinsic motor function after distal ulnar lesions in three patients.

In 2017, Colonna et al. ${ }^{[36]}$ suggested using the branch for the first lumbrical as a babysitter for the deep motor branch of the ulnar nerve to avoid intrinsic atrophy. This hypothesis was based on anatomical studies and qualitative and quantitative analysis of nerve fibers.

In 2018, Bertelli et al. ${ }^{[37]}$ described nerve transfer from the motor branch of the opponens pollicis (OPB) to the deep branch of the ulnar nerve in the terminal division (TDDBUN) to increase pinch strength. With promising results, they suggested combining transfers from the OPB to the TDDBUN and distal AIN to the motor branch of the ulnar nerve for reconstruction.

\section{Median nerve}

In sensory nerve transfers for the median nerve, the fundamental aim is to restore sensitivity of the thumb and index finger to ensure pinch and grip functions, which are essential for fine motor tasks ${ }^{[38]}$. 


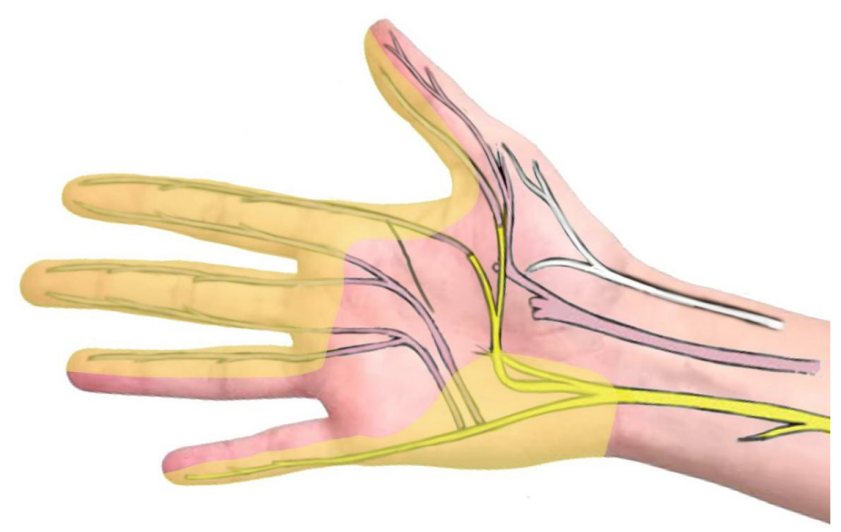

Figure 4. The fourth digital nerve is transferred end-to-end to the first digital nerve. The remaining median-dependent distal stumps are coapted end-to-side. Yellow: functional nerves; lighter yellow: sensitive areas; pink: nonfunctional nerves

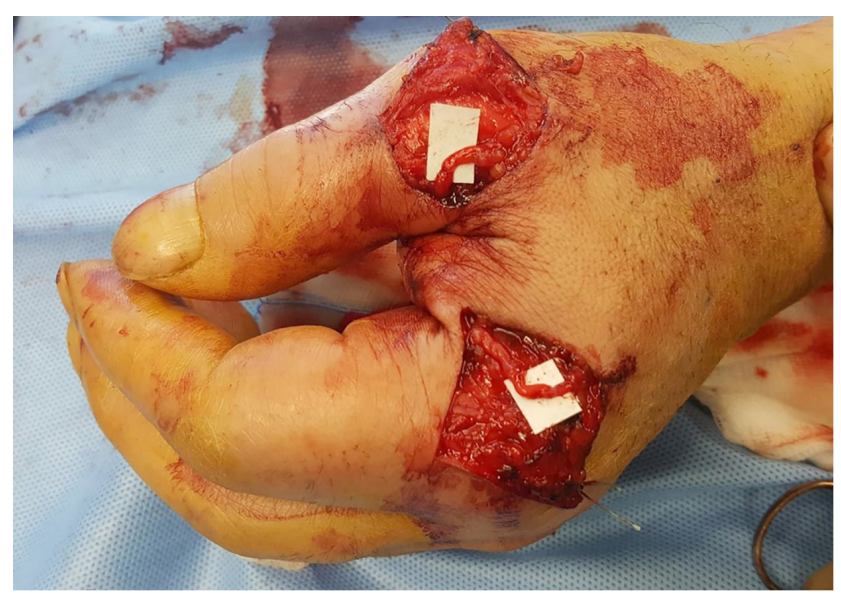

Figure 5. Very distal sensory nerve transfer described by Bertelli: sensory dorsal radial nerve branches coapted to the palmar nerves at the level of the metacarpal-phalangeal joint

The recovery of sensory function is not influenced by timing as motor function is. However, it must be remembered that a classic nerve graft in a high median lesion translates into recovery times for sensation of more than a year; this also results in long recovery times without protective sensitivity ${ }^{[39,40]}$.

For these reasons, different fiber donors have been considered to restore sensation to the critical median nerve, depending on availability.

In isolated lesions of the median nerve, one possibility is to sacrifice the digital nerve directed to the fourth interdigital space and innervated by the ulnar nerve, to re-innervate the first interdigital space, in particular the ulnar margin of the first finger and the radial margin of the second finger. This nerve transfer is done end-to-end ${ }^{[4]}$. To ensure proprioception in non-critical areas, end-to-side coaptations are performed between the distal stumps of these areas and a functioning sensory branch [Figure 4].

Another option in high median nerve injuries is to use the dorsal sensory branch from the radial nerve ${ }^{[41,42]}$.

Bertelli et al. ${ }^{[43]}$ described promising results with a "very distal nerve transfer" from dorsal branches of the radial nerve to palmar nerves at the level of the proximal phalanx [Figure 5]. 


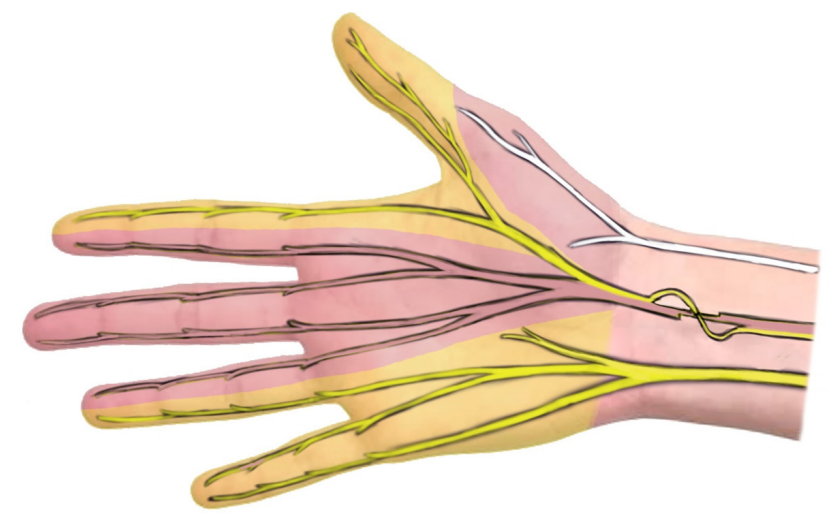

Figure 6. Transfer of sensation with transposition of fascicles for the third to the first web space. Yellow: functional nerves; lighter yellow: sensitive areas; pink: nonfunctional nerves; lighter pink: non sensitive areas

In incomplete lesions of the median nerve or high lesions of the brachial plexus (C5-C6 $)^{[44]}$, the sensory component for the third interdigital space can be preserved since it originates from a distinct fascicle. This fascicle can be dissected up to the distal forearm and coapted to the distal portion of the fascicle for the first web space in order to restore critical sensitivity between the thumb and index finger [Figure 6]. It is possible to access both the recipient and donor nerves nearby through a single incision. This technique also avoids performing a sensory nerve transfer in the hand, thereby avoiding scarring on the palmar surface of the hand itself. In addition, the repair is quick and easy to achieve ${ }^{[45]}$. The distal stumps of the donor fascicle are also coapted end-to-side to the functional fascicles to maintain protective sensation in the donor site.

\section{Fourth web space digital nerve to first web space digital nerve transfer: technique}

A classic incision is made over the carpal tunnel and extended to the first and fourth web spaces with zigzag Bruner-Type incisions. Under the superficial arterial arch, the branches of the median and ulnar nerves are identified. The branch to the fourth web space is followed and divided as distally as possible, which corresponds to the heads of the metacarpals. The nerve to the first web space is dissected proximally in order to achieve a length that allows tensionless coaptation. When an adequate length is obtained, the median-dependent branch is cut proximally and transferred to the proximal stump of the fourth digital nerve, which is dependent on the ulnar nerve. All other remaining sensory nerves are coapted end-to-side, as in Figure 4, to restore protective sensation.

Very distal sensory nerve transfers in high median nerve lesions: technique

The surgeon makes a $\mathrm{V}$ incision on the radial side of the metacarpophalangeal joint of the second finger. This incision exposes the dorsal sensory branch of the radial nerve and the radial collateral of the digital nerve of the second finger from the median nerve. These are divided in such a way that the proximal stump of the dorsal sensory branch for the second finger can be sutured end-to-end to the distal stump of the radial collateral of the proper digital nerve. Another V-shaped skin incision is performed, centered on the ulnar side of the metacarpophalangeal joint of the first finger, and the dorsal sensory branch and the digital collateral nerve are identified. These are subsequently divided and coapted as previously described for the second finger.

\section{Radial nerve}

The sensibility of the dorsum of the hand can be re-established via the lateral antebrachial cutaneous nerve (LACN) due to its characteristics. The LACN runs near the sensory radial branch of the distal forearm. Its dimensions are suitable for end-to-end coaptation, which can restore a large area of sensation to the back of the hand, by sacrificing a critical distal distribution. The LACN is also expendable and its use does not create significant morbidity along its supplied territory ${ }^{[4]}$. 


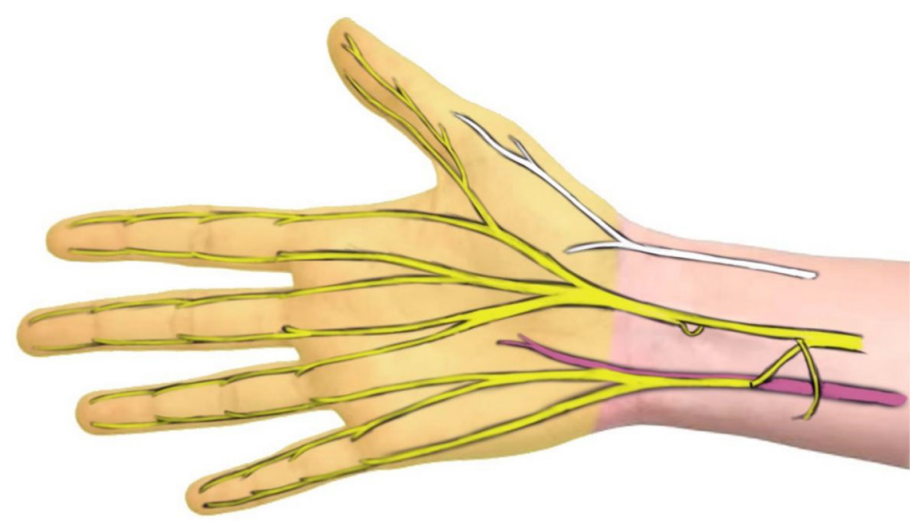

Figure 7. Nerve transfers in an end-to-end strategy to restore ulnar sensation. Protective sensation of the third web space is maintained through end-to-side coaptation of the distal stump on the sensitive portion of the median nerve itself

The back of the hand supplied by the radial nerve is not critical. This has prompted some authors to suggest end-to-side coaptation on the functioning median nerve and indeed, this has been performed in many clinical scenarios ${ }^{[46-49]}$. Experimental data have also shown that the axons transmitted in these end-to-side strategies provide maximum protective sensation ${ }^{[0,51]}$.

Recently, Somsak suggested an end-to-side transfer as a treatment for C5-C6 root avulsions. In addition to the loss of sensation, such patients may experience pain on the dorsoradial aspect of the hand. An endto-side transfer between the superficial branch of the radial nerve to the ulnovolar portion of the median nerve has shown promise in relieving pain and providing protective sensation ${ }^{[52]}$.

\section{Ulnar nerve}

Sensory nerve transfers for isolated ulnar nerve injuries aim to reestablish protective sensation to the ulnar border of the hand ${ }^{[53]}$. In the literature, several methods have been proposed by different authors to utilize the functioning median nerve in order to provide sensation to the distribution of the ulnar nerve.

In the event of a brachial plexus or high ulnar nerve injury, the nerve directed to the third web space can be used to restore sensation to the ulnar border of the hand, which is more critical ${ }^{[22]}$.

Brown et al. ${ }^{[54]}$ described end-to-end coaptation between the proximal stump of the nerve of the third web space and the distal stump of the nerve for the fourth web space in the distal forearm.

Furthermore, the dorsal sensory branch of the ulnar nerve is coapted end-to-side to the sensory part of the median nerve after making an epineural opening [Figure 7].

Flores reported an analogous approach, with the use of an end-to-side technique ${ }^{[55]}$.

The sensitivity of the ulnar side of the hand can, in fact, be restored with end-to-side nerve transfers. This can be done using the median branch to the third web space as a donor. Another possible technique involves coaptation of the sensitive branches of the ulnar nerve with the functional median nerve at the level of the forearm ${ }^{[16]}$. These techniques allow restoration of the sensitivity of the ulnar border of the hand without denervation of the territories supplied by the median nerve.

Oberlin et al. ${ }^{[56]}$ described coaptation in the distal forearm with an interpositional nerve graft between the LACN and the dorsal branch of the ulnar nerve. Ruchelsman et al. ${ }^{[57]}$ described a revised technique, which avoids the use of an interpositional graft through dissection for a longer LACN. 
Table 1. Motory nerve transfers in distal forearm and in the hand

\begin{tabular}{|c|c|c|c|c|c|c|}
\hline & Recipient & Donor & Modality & Advantage & Disvantage & Ref. \\
\hline \multirow[t]{5}{*}{$\begin{array}{l}\text { Median } \\
\text { N. Lesion }\end{array}$} & TBMN & $\begin{array}{l}\text { AIN } \\
\text { (Pronator) }\end{array}$ & End-to-End & Congruous number of Axon & $\begin{array}{l}\text { Not available in high median nerve } \\
\text { lesion } \\
\text { Interpositional nerve graft needed }\end{array}$ & {$[10-12]$} \\
\hline & TBMN & EDMNB & End-to-End & & Unclear results & {$[4]$} \\
\hline & TBMN & ECUMB & End-to-End & & Unclear results & {$[4]$} \\
\hline & TBMN & TLMB & End-to-End & & Unclear results & {$[13]$} \\
\hline & TBMN & ADQMB & End-to-End & No need of interpositional nerve graft & & [14] \\
\hline \multirow[t]{7}{*}{$\begin{array}{l}\text { Ulnar N. } \\
\text { Lesion }\end{array}$} & MBUN & $\begin{array}{l}\text { AIN } \\
\text { (Pronator) }\end{array}$ & End-to-End & $\begin{array}{l}\text { No need of interpositional nerve graft } \\
\text { Reliable technique }\end{array}$ & $\begin{array}{l}\text { Dispersion of axons to the hypotenar } \\
\text { musculature }\end{array}$ & {$[4,22,25]$} \\
\hline & MBUN & $\begin{array}{l}\text { AIN } \\
\text { (Pronator) }\end{array}$ & SETS & $\begin{array}{l}\text { Allow the ulnar nerve to regenerate } \\
\text { spontaneously }\end{array}$ & Unclear results & {$[30,31]$} \\
\hline & MBUN & MBMN & DBNG & $\begin{array}{l}\text { Allow the ulnar nerve to regenerate } \\
\text { spontaneously }\end{array}$ & $\begin{array}{l}\text { Interpositional nerve graft needed } \\
\text { Unclear results }\end{array}$ & {$[32]$} \\
\hline & MBUN & EDMNB & End-to-End & Low morbidity & $\begin{array}{l}\text { Interpositional nerve graft needed } \\
\text { Suboptimal results }\end{array}$ & {$[34]$} \\
\hline & MBUN & ECUMB & End-to-End & Low morbidity & $\begin{array}{l}\text { Interpositional nerve graft needed } \\
\text { Suboptimal results }\end{array}$ & {$[34]$} \\
\hline & DMBUN & TBMN & DBNG & $\begin{array}{l}\text { Allow the ulnar nerve to regenerate } \\
\text { spontaneously }\end{array}$ & Interpositional nerve graft needed & {$[35]$} \\
\hline & TDDBUN & OPB & End-to-End & $\begin{array}{l}\text { Very distal transfer } \\
\text { Can restore pinch strength } \\
\text { Could be combined with the AIN } \\
\text { nerve transfer }\end{array}$ & & {$[37]$} \\
\hline
\end{tabular}

TBMN: Thenar branch of median nerve; AIN: anterior interosseous nerve; EDMNB: extensor digiti minimi motor branch; ECUMB: extensor carpi ulnaris motor branch; TLMB: third lumbrical motor branch; ADQMB: abductor digiti quinti motor branch; MBUN: motor branch of ulnar nerve; SETS: supercharged end to side; MBMN: motor branch of median nerve; DBNG: double bridging nerve graft; DMBUN: deep motor branch of ulnar nerve; TDDBUN: terminal division deep branch of the ulnar nerve; OPB: opponens pollicis branch

Other strategies involve direct end-to-end coaptation including between the palmar cutaneous branch of the median nerve as donors and the ulnar dorsal nerve ${ }^{[22,56,58]}$.

\section{Nerve transfers to restore ulnar sensation: technique}

Nerve transfers to restore sensation of the ulnar nerve are generally performed simultaneously with motor transfers. Sensory fascicles of the ulnar nerve are dissected proximally. Distal to the carpal tunnel, it is possible to recognize the fascicles directed to the third interdigital space. These are dissected proximally to the distal forearm. Here the sensory fascicles of the ulnar nerve and the fascicles directed to the third web space are coapted end-to-end as illustrated in Figure 7. The dorsal cutaneous ulnar branch is divided proximally and transferred, tension free, to the median nerve. Protective sensation of the third web space is maintained through end-to-side coaptation between the distal stump of the fascicle and the sensitive portion of the median nerve itself.

\section{CONCLUSION}

Nerve transfers in the distal forearm and hand appear to be a viable and promising option in patients with peripheral nerve injuries. The numerous advantages offered by transposition of a functional nerve stump near the effector muscle have opened up new alternatives to nerve grafts and tendon transfers, for the treatment of nerve injuries. The surgeon who performs brachial plexus surgery must be able to provide the best treatment for the patient and his needs. The complexity of the anatomical components and the density of the nerve structures in the distal forearm and hand give rise to various reconstructive possibilities. The main nerve transfers of the distal forearm and in the hand have been summarized in Tables 1 and 2. The addition of new concepts such as very distal nerve transfers and end-to-side coaptations have led to new solutions for previous problems in which solutions were more complex and are sometimes associated with 
Table 2. Sensory Nerve Transfers in distal forearm and in the hand

\begin{tabular}{|c|c|c|c|c|c|c|}
\hline & Recipient & Donor & Modality & Advantage & Disvantage & Ref. \\
\hline \multirow[t]{3}{*}{$\begin{array}{l}\text { Median N. } \\
\text { Lesion }\end{array}$} & $\begin{array}{l}\text { I Digital Branch } \\
+ \\
\text { II and III } \\
\text { Digital Branch }\end{array}$ & $\begin{array}{l}\text { IV Digital } \\
\text { Branch } \\
\text { Ulnar Sensory } \\
\text { Branch }\end{array}$ & $\begin{array}{l}\text { End-to-End } \\
\text { End-to-Side }\end{array}$ & $\begin{array}{l}\text { Restore sensitivity of the thumb } \\
\text { and index finger } \\
\text { Proprioceptive sensitivity in non- } \\
\text { critical areas }\end{array}$ & $\begin{array}{l}\text { Loss of sensitivity of the IV web } \\
\text { space }\end{array}$ & {$[4]$} \\
\hline & $\begin{array}{l}\text { Collateral } \\
\text { Digital Nerve } \\
\text { in the I Web } \\
\text { space }\end{array}$ & $\begin{array}{l}\text { Sensory Dorsal } \\
\text { Branch of } \\
\text { Radial Nerve }\end{array}$ & End-to-End & $\begin{array}{l}\text { Restore sensitivity of the thumb } \\
\text { and index finger } \\
\text { Maintain proprioceptive } \\
\text { sensitivity in donor areas due to } \\
\text { an end-to-side coaptation for } \\
\text { the distal dorsal stumps }\end{array}$ & $\begin{array}{l}\text { Provide just protective } \\
\text { sensitivity }\end{array}$ & {$[41-43]$} \\
\hline & $\begin{array}{l}\text { Component for } \\
\text { I digital nerve }\end{array}$ & $\begin{array}{l}\text { Component for } \\
\text { III digital nerve }\end{array}$ & End-to-End & Useful in cases of C5-C6 lesions & $\begin{array}{l}\text { Loss of sensitivity of the IV web } \\
\text { space }\end{array}$ & {$[44]$} \\
\hline \multirow[t]{2}{*}{$\begin{array}{l}\text { Radial N. } \\
\text { Lesion }\end{array}$} & $\begin{array}{l}\text { Radial Sensory } \\
\text { Branch }\end{array}$ & LACN & End-to-End & $\begin{array}{l}\text { Dimensions comparable for the } \\
\text { coapation } \\
\text { Donor runs near the recipient }\end{array}$ & & [4] \\
\hline & $\begin{array}{l}\text { Radial Sensory } \\
\text { Branch }\end{array}$ & Median Nerve & End-to-Side & $\begin{array}{l}\text { No loss of sensitivity } \\
\text { Useful in cases of C5-C6 lesions }\end{array}$ & $\begin{array}{l}\text { Provide just protective } \\
\text { sensitivity }\end{array}$ & {$[52]$} \\
\hline \multirow[t]{6}{*}{$\begin{array}{l}\text { Ulnar N. } \\
\text { Lesion }\end{array}$} & $\begin{array}{l}\text { Ulnar Sensory } \\
\text { Branch }\end{array}$ & $\begin{array}{l}\text { III Digital } \\
\text { Branch }\end{array}$ & End-to-End & $\begin{array}{l}\text { Restore sensitivity of the ulnar } \\
\text { border of the hand }\end{array}$ & $\begin{array}{l}\text { Proprioceptive sensitivity in } \\
\text { donor areas due to an end-to- } \\
\text { side coaptation for the distal } \\
\text { stumps }\end{array}$ & {$[54]$} \\
\hline & $\begin{array}{l}\text { Ulnar Sensory } \\
\text { Branch }\end{array}$ & $\begin{array}{l}\text { III Digital } \\
\text { Branch }\end{array}$ & End-to-Side & No loss of sensitivity & $\begin{array}{l}\text { Provide just protective sensitivity } \\
\text { of the ulnar border of the hand }\end{array}$ & {$[55]$} \\
\hline & $\begin{array}{l}\text { Ulnar Sensory } \\
\text { Branch }\end{array}$ & $\begin{array}{l}\text { Median nerve } \\
\text { branch in } \\
\text { forearm }\end{array}$ & End-to-End & $\begin{array}{l}\text { No scar in the hand } \\
\text { Restore sensitivity of the ulnar } \\
\text { border of the hand }\end{array}$ & $\begin{array}{l}\text { Protective sensitivity for the } \\
\text { third web space through an end- } \\
\text { to-side strategy }\end{array}$ & {$[16]$} \\
\hline & $\begin{array}{l}\text { Ulnar Sensory } \\
\text { Branch }\end{array}$ & $\begin{array}{l}\text { Median nerve } \\
\text { branch in } \\
\text { forearm }\end{array}$ & End-to-Side & $\begin{array}{l}\text { No scar in the hand } \\
\text { lloss of sensitivity }\end{array}$ & $\begin{array}{l}\text { Provide just protective sensitivity } \\
\text { of the ulnar border of the hand }\end{array}$ & {$[16]$} \\
\hline & $\begin{array}{l}\text { Dorsal Ulnar } \\
\text { Sensory } \\
\text { Branch }\end{array}$ & LACN & End-to-Side & No loss of sensitivity & $\begin{array}{l}\text { Provide just protective } \\
\text { sensitivity }\end{array}$ & {$[56,57]$} \\
\hline & $\begin{array}{l}\text { Ulnar Sensory } \\
\text { Branch }\end{array}$ & PCBMN & End-to-End & $\begin{array}{l}\text { Restore sensitivity of the ulnar } \\
\text { border of the hand }\end{array}$ & $\begin{array}{l}\text { Proprioceptive sensitivity in } \\
\text { donor areas due to an end-to- } \\
\text { side coaptation for the distal } \\
\text { stumps }\end{array}$ & {$[22,56,58]$} \\
\hline
\end{tabular}

LACN: lateral antebrachial cutaneous nerve; PCBMN: palmar cutaneous branch of median nerve

greater morbidity. Such techniques can be found in the recent literature but require further study because some of them remain isolated case reports.

\section{DECLARATIONS}

\section{Authors' contributions}

Concept and design: Colonna MR

Data acquisition, data analysis, manuscript preparation: Costa $\mathrm{AL}$

Critical revision and completion of manuscript: Costa AL, Titolo P, Battiston B, Colonna MR

\section{Availability of data and materials}

Not applicable.

\section{Financial support and sponsorship}

None.

\section{Conflicts of interest}

All authors declare that there are no conflicts of interest. 


\section{Ethical approval and consent to participate}

Not applicable.

\section{Consent for publication}

All patients underwent surgical procedures with informed consent that described in detail the procedure and any alternatives. The patients also signed a separate consent for the processing of sensitive data and the recording of photos and videos for educational, illustrative and research purposes.

\section{Copyright}

(C) The Author(s) 2020.

\section{REFERENCES}

1. Tung TH, Novak CB, Mackinnon SE. Nerve transfers to the biceps and brachialis branches to improve elbow flex- ion strength after brachial plexus injuries. J Neurosurg 2003;98:313-8.

2. Tung TH, Mackinnon SE. Brachial plexus injuries. Clin Plast Surg 2003;30:269-87.

3. Tung TH, Mackinnon SE. Nerve transfers: Indications, techniques, and outcomes. J Hand Surg Am 2010;35:332-41.

4. Brown JM, Mackinnon SE. Nerve transfers in the forearm and hand. Hand Clin 2008;24:319-40.

5. Imbriglia JE, Hagberg WC, Baratz ME. Median nerve reconstruction. In: Peimer CA, editor. Surgery of the hand and upper extremity, vol II. New York: McGraw-Hill; 1996. p. 1381.

6. Davis TRC. Median nerve palsy. In: Green DP, Hotchkiss RN, Pederson WC, editors. Green’s operative hand surgery. 5th edition. Philadelphia: Elsevier; 2005. p. 1131.

7. Bertelli JA, Soldado F, Lehn VL, Ghizoni MF. Reappraisal of clinical deficits following high median nerve injuries. J Hand Surg Am 2016;41:13-9.

8. Humphreys DB, Mackinnon SE. Nerve transfers. Operat Tech Plast Reconstr Surg 2003;9:89, 7-11.

9. Mackinnon SE, Dellon AL. Anatomic investigations of nerves at the wrist: I. Orientation of the motor fascicle of the median nerve in the carpal tunnel. Ann Plast Surg 1988;21:32-5.

10. Vernadakis AJ, Humphreys DB, Mackinnon SE. Distal anterior interosseous nerve in the recurrent motor branch graft for reconstruction of a median nerve neuroma-in-continuity. J Reconstr Microsurg 2004;20:7-11.

11. Haase SC, Chung KC. Anterior interosseous nerve transfer to the motor branch of the ulnar nerve for high ulnar nerve injuries. Ann Plast Surg 2002;49:285-90.

12. Ustun ME, Ogun TC, Karabulut AK, Büyükmumcu M. An alternative method for restoring opposition after median nerve injury: an anatomical feasibility study for the use of neurotisation. J Anat 2001;198:635-8.

13. Schultz RJ, Aiache A. An operation to restore opposition of the thumb by nerve transfer. Arch Surg 1972;105:777-9.

14. Bertelli JA, Soldado F, Rodrígues-Baeza A, Ghizoni MF. Transfer of the motor branch of the abductor digiti quinti for thenar muscle reinnervation in high median nerve injuries. J Hand Surg Am 2018;43:8-15.

15. Tse R, Hentz VR, Yao J. Late reconstruction for ulnar nerve palsy. Hand Clin 2007;23:373-92

16. Bertelli JA. Prior to repair functional deficits in above- and below-elbow ulnar nerve injury. J Hand Surg Am 2020; doi: 10.1016/ j.jhsa.2019.10.033.

17. Weber RV, Mackinnon SE. Upper extremity nerve transfers. In: Slutsky DJ, Hentz VR, editors. Peripheral nerve surgery: practical applications in the upper extremity. Philadelphia: Churchill Living- stone Elsevier; 2006. p. 89.

18. Kim DH, Han K, Tiel RL, Murovic JD, Kline DG. Surgical outcomes of 654 ulnar nerve lesions. J Neurosurg 2003;98:993-1004.

19. Lester RL, Smith PJ, Mott G, McAllister RM. Intrinsic reinnervation- myth or reality? J Hand Surg 1993;18:454-60.

20. Gaul JS Jr. Intrinsic motor recovery: a long-term study of ulnar nerve repair. J Hand Surg Am 1982;7:502-8.

21. Wang Y, Zhu S. Transfer of a branch of the anterior interosseous nerve to the motor branch of the median nerve and ulnar nerve. Chin Med J (Engl) 1997;110:216-9.

22. Battiston B, Lanzetta M. Reconstruction of high ulnar nerve lesions by distal double median to ulnar nerve transfer. J Hand Surg Am 1999;24:1185-91.

23. Haase SC, Chung KC. Anterior interosseous nerve transfer to the motor branch of the ulnar nerve for high ulnar nerve injuries. Ann Plast Surg 2002;49:285-90.

24. Novak CB, Mackinnon SE. Distal anterior interosseous nerve transfer to the deep motor branch of the ulnar nerve for reconstruction of high ulnar nerve injuries. J Reconstr Microsurg 2002;18:459-64.

25. Brown JM, Yee A, Mackinnon SE. Distal median to ulnar nerve transfers to restore ulnar motor and sensory function within the hand: technical nuances. Neurosurgery 2009;65:966-78.

26. Kale SS, Glaus SW, Yee A, Nicoson MC, Hunter DA, et al. Reverse end-to-side nerve transfer: from animal model to clinical use. J Hand Surg Am 2011;36:1631-9.e2.

27. Farber SJ, Glaus SW, Moore AM, Hunter DA, Mackinnon SE, et al. Supercharge nerve transfer to enhance motor recovery: a laboratory study. J Hand Surg Am 2013;38:466-77. 
28. Barbour J, Yee A, Kahn LC, Mackinnon SE. Supercharged end-to-side anterior interosseous to ulnar motor nerve transfer for intrinsic musculature reinnervation. J Hand Surg Am 2012;37:2150-9.

29. Boutros S, Nath RK, Yüksel E, Weinfeld AB, Mackinnon SE. Transfer of flexor carpi ulnaris branch of the ulnar nerve to the pronator teres nerve: Histomorphometric analysis. J Reconstr Microsurg 1999;15:119-22.

30. Baltzer H, Woo A, Oh C, Moran SL. Comparison of ulnar intrinsic function following supercharge end-to-side anterior interosseous-toulnar motor nerve transfer: a matched cohort study of proximal ulnar nerve injury patients. Plast Reconstr Surg 2016;138:1264-72.

31. Koriem E, El-Mahy MM, Atiyya AN, Diab RA. Comparison between supercharged ulnar nerve repair by anterior interosseous nerve transfer and isolated ulnar nerve repair in proximal ulnar nerve injuries. J Hand Surg Am 2020;45:104-10.

32. Magdi Sherif M, Amr AH. Intrinsic hand muscle reinnervation by median-ulnar end-to-side bridge nerve graft: case report. J Hand Surg Am 2010;35:446-50.

33. Colonna MR, Russo A, Galeano M, Delia G, Pajardi GE, et al. "Babysitting" procedures in proximal nerve trunk injuries: two case reports and a review. Plast Aesthet Res 2015;2:208-12.

34. Barbour JR, Gontre G, Daliwal G, Mackinnon SE, Tung TH. Transfer of the extensor digit quinti and extensor carpi ulnaris branches of the posterior interosseous nerve to the motor branch of the ulnar nerve to restore intrinsic hand function: case report and anatomic study. J Hand Surg Am 2012;38:98-103.

35. Gesslbauer B, Furtmüller GJ, Schuhfried O, Roche AD, Sporer M, et al. Nerve grafts bridging the thenar branch of the median nerve to the ulnar nerve to enhance nerve recovery: a report of three cases. J Hand Surg Eur Vol 2017;42:281-5.

36. Colonna MR, Pino D, Battiston B, d'Alcontres FS, Natsis K, et al. Distal nerve transfer from the median nerve lumbrical fibers to the distal ulnar nerve motor branches in the palm: an anatomical cadaveric study. Microsurgery 2019;39:434-40.

37. Bertelli JA, Soldado F, Rodrígues-Baeza A, Ghizoni MF. Transferring the motor branch of the opponens pollicis to the terminal division of the deep branch of the ulnar nerve for pinch reconstruction. J Hand Surg Am 2019;44:9-17.

38. Ebied AM, Kemp GJ, Frostick SP. The role of cutaneous sensation in the motor function of the hand. J Orthop Res 2004;22:862-6.

39. Nath RK, Mackinnon SE, Shenaq SM. New nerve transfers following peripheral nerve injuries. Operat Tech Plast Reconstr Surg 1997;4:2-11.

40. Imbriglia JE, Hagberg WC, Baratz ME. Median nerve reconstruction. In: Peimer CA, editor. Surgery of the hand and upper extremity, vol II. New York: McGraw-Hill; 1996. p. 1381.

41. García-López A, Sebastian P, Martinez F, Perea D. Transfer of the nerve to the brachioradialis muscle to the anterior interosseous nerve for treatment for lower brachial plexus lesions: case report. J Hand Surg Am 2011;36:394-7.

42. Rapp E, Lallemand S, Ehrler S, Buch N, Foucher G. Restoration of sensation over the contact surfaces of the thumb-index pinch grip using the terminal branches of the superficial branch of the radial nerve. Chir Main 1999;18:179-83.

43. Bertelli JA, Ghizoni MF. Very distal sensory nerve transfers in high median nerve lesions. J Hand Surg Am 2011;36:387-93.

44. Ross D, Mackinnon SE, Chang YL. Intraneural anatomy of the median nerve provides "third web space" donor nerve graft. J Reconstr Microsurg 1992;8:225-32.

45. Cheng J. Nerve transfers for digital sensation. In: Slutsky DJ, editor. Master skills in nerve repair: tips and techniques. Rosemont (IL): ASSH; 2008.

46. Mennen U. End-to-side nerve suture in clinical practice Hand Surg 2003;8:33-42.

47. Pienaar C, Swan MC, De Jager W, Solomons M. Clinical experience with end-to-side nerve transfer. J Hand Surg 2004;29:438-43.

48. Brenner MJ, Dvali L, Hunter DA, Myckatyn TM, Mackinnon SE. Motor neuron regeneration through end-to-side repairs is a function of donor nerve axotomy. Plast Reconstr Surg 2007;120:215-23.

49. Amr SM, Moharram AN. Repair of brachial plexus lesions by end-to-side side-to-side grafting neurorrhaphy: experience based on 11 cases. Microsurgery 2005;25:126-46.

50. Tarasidis G, Watanabe O, Mackinnon SE, Strasberg SR, Haughey BH, et al. End-to-side neurorraphy: a long-term study of neural regeneration in a rat model. Otolaryngol Head Neck Surg 1998;119:337-41.

51. Tarasidis G, Watanabe O, Mackinnon SE, Strasberg SR, Haughey BH, et al. End-to-side neurorrhaphy resulting in limited sensory axonal regeneration in a rat model. Ann Otol Rhinol Laryngol 1997;106:506-12.

52. Somsak L, Kittipod N, Kanchai M, Chairoj U, Kiat W, et al. End-to-side radial sensory to median nerve transfer to restore sensation and relieve pain in C5 and C6 nerve root avulsion. J Hand Surg 2011;36A:209-15.

53. Anderson GA. Ulnar nerve palsy. In: Green DP, Hotchkiss RN, Pederson WC, editors. Green's operative hand surgery. 5th edition. Philadelphia: Elsevier; 2005. p. 1162.

54. Brown JM, Yee A, Mackinnon SE. Distal median to ulnar nerve transfers to restore ulnar motor and sensory function within the hand: technical nuances. Neurosurgery 2009;65:966-78.

55. Flores LP. Distal anterior interosseous nerve transfer to the deep ulnar nerve and end-to-side suture of the superficial ulnar nerve to the third common palmar digital nerve for treatment of high ulnar nerve injuries: experience in five cases. Arq Neuropsiquiatr 2011;69:519-24.

56. Oberlin C, Teboul F, Severin S, Beaulieu JY. Transfer of the lateral cutaneous nerve of the forearm to the dorsal branch of the ulnar nerve, for providing sensation on the ulnar aspect of the hand. Plast Reconstr Surg 2003;112:1498-500.

57. Ruchelsman DE, Price AE, Valencia H, Ramos LE, Grossman JA. Sensory restoration by lateral antebrachial cutaneous to ulnar nerve transfer in children with global brachial plexus injuries. Hand (N Y) 2010;5:370-3.

58. Sassu P, Libberecht K, Nilsson A. Nerve transfers of the forearm and hand: a review of current indications. Plast Aesthet Res 2015;2:195-201. 